See Article page 164 .

\section{Commentary: Changing the equation by boosting the numerator}

\author{
Sara Najmeh, MD, and Matthew G. Hartwig, MD
}

Despite all the recent advances in organ-procurement organizations, allocation system, increased use of extended-criteria donors, use of lungs from donation after cardiac death donors, and increase in number of centers performing lung transplants globally, the number of patients requiring lung transplant each year continues to grow. Even though the number of donors continues to steadily increase, in the United States fewer than 1 in 4 pairs of lungs offered for donation will be eventually used for transplant, and hundreds of thousands of people around the world continue to die each year from end-stage lung disease. ${ }^{1}$ Instead of focusing on increasing the denominator, or the number of available donors, the Toronto group began focusing a number of years ago on the numerator, or number of donor organs deemed suitable for transplantation.

Stopping to reflect upon it, the current way of assessing a donor's lungs is remarkably inefficient. Today, transplant professionals review the donor's history, thoracic imaging, bronchoscopy findings, and function. The critical and expensive next step consists of traveling to the donor hospital for a more direct and final assessment of the organ. In vivo examination of the lungs allows the surgeon to evaluate the lung compliance and inspect any abnormal areas identified on previous imaging. If the organ is deemed "inadequate" by the procuring surgeon at that time, the process usually terminates and the organ is discarded with very minimal chance of reallocation due to time constraints.

\footnotetext{
From the Division of Cardiovascular and Thoracic Surgery, Department of Surgery, Duke University Medical Center, Durham, NC.

Disclosures: The authors reported no conflicts of interest.

The Journal policy requires editors and reviewers to disclose conflicts of interest and to decline handling or reviewing manuscripts for which they may have a conflict of interest. The editors and reviewers of this article have no conflicts of interest.

Received for publication June 5, 2020; revisions received June 5, 2020; accepted for publication June 12, 2020; available ahead of print July 22, 2020.

Address for reprints: Matthew G. Hartwig, MD, DUMC 3863, Durham, NC 27710 (E-mail: Matthew.hartwig@duke.edu).

JTCVS Open 2020;3:171-2

2666-2736

Copyright (C) 2020 The Authors. Published by Elsevier Inc. on behalf of The American Association for Thoracic Surgery. This is an open access article under the CC BY-NCND license (http://creativecommons.org/licenses/by-nc-nd/4.0/).

https://doi.org/10.1016/j.xjon.2020.06.003
}

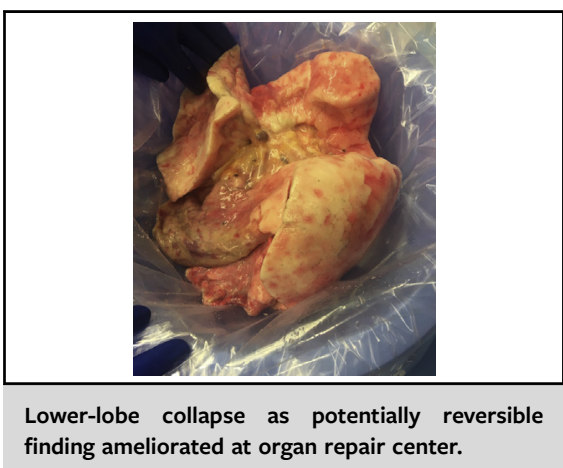

\section{CENTRAL MESSAGE \\ Our current methods of organ \\ assessment and procurement \\ harken from over half a century \\ ago. Dr Keshavjee provides us \\ here with a thoughtfully \\ articulated version of the not-so- \\ distant future.}

This process of donor lung assessment undoubtedly leads to loss of potentially good allografts.

Dr Keshavjee's re-imagination of the organ-management ecosystem has never been more relevant. In his model, organs from the same donor are transported to a central organ repair and optimization center, where experts can further evaluate, treat, and potentially improve the organs from the state in which they were retrieved before sending them out to the implanting centers. This process not only expands the number of organs that will be deemed fit for transplant as demonstrated by the Toronto group experience $^{2}$ but may also drastically change the whole dynamic of the transplant experience by allowing organ enhancements to occur and making transplant surgery a more scheduled practice. ${ }^{3}$

The gap between the current state of lung assessment and selection and the data presented in this work is a sizeable one, and many more mundane but important biological, economical, and logistical details require resolution. Although the financial impact remains unclear when considering the multiple layers of the procurement process undergoing change, many experts voice concerns about the overall economic implications on the health care system. Others have raised biological concerns, such as the possible adverse impact of 2 disparate cold ischemic periods on the organs. ${ }^{4}$ More importantly, the willingness of surgeons to 
change their existing practice and adopt this new approach might be toughest mountain to climb. Interestingly, the ongoing coronavirus 2019 pandemic has made us question the process of having multiple procuring teams from different centers travel to the donor hospital and has forcibly altered surgeons' acceptance of other personnel procuring their recipient's organs.

Alternative, but analogous, systems can also be envisioned. As technology improves, we imagine easily portable, reliable, and cost-effective organ-preservation devices that allow for normothermic evaluation and rehabilitation during travel. Facing a need for broader geographic sharing in the United States, newly imposed travel restrictions, and a desire to minimize the cost and risk to procurement teams, trained specialists at regional procurement centers could routinely obtain donated organs, place them on perfusion devices, and transport the organs to the most appropriate recipient wherever they may be geographically located. A lung in Hawaii could be procured one day, transported to the East Coast of the United States 4500 miles away, and safely be transplanted 24 hours later.
Although the details remain to be determined, it is clear that our "modern" methods of organ assessment and procurement harken from over half a century ago. Dr Keshavjee provides us with a thoughtfully articulated version of the not-so-distant future. ${ }^{5}$ The time is now for the transplant community to move this important agenda forward for the benefit of all patients who suffer from end-stage organ disease.

\section{References}

1. Valapour M, Lehr CJ, Skeans MA, Smith JM, Uccellini K, Goff R, et al. OPTN/SRTR 2018 annual data report: lung. Am J Transplant. 2020; 20(suppl s1):427-508.

2. Chang SH, Kreisel D, Marklin GF, Cook L, Hachem R, Kozower BD, et al. Lung focused resuscitation at a specialized donor care facility improves lung procurement rates. Ann Thorac Surg. 2018;105:1531-6.

3. Cypel M, Yeung JC, Keshavjee S. Introducing the concept of semielective lung transplantation through the use of ex vivo lung perfusion. J Thorac Cardiovasc Surg. 2018;156:2350-2.

4. Leiva-Juárez MM, Urso A, Arango Tomás E, Lederer DJ, Sanchez P, Griffith B, et al. Extended post-ex vivo lung perfusion cold preservation predicts primary graft dysfunction and mortality: results from a multicentric study. J Heart Lung Transplant. May 16, 2020 [Epub ahead of print].

5. Keshavjee S. Human organ repair centers: fact or fiction? J Thorac Cardiovasc Surg Open. 2020;3:164-8. 